\title{
Crítica da esquerda, crítica da razão - uma visão de conjunto sobre o pensamento de Horkheimer nos anos $1940^{*}$
}

\author{
Critique of the Left, Critique of Reason - An Overview on Horkheimer's \\ Thought in the 1940s
}

\author{
Luiz Repa \\ luizrepa@usp.br \\ (Universidade de São Paulo/CEBRAP, São Paulo, Brasil)
}

\begin{abstract}
Resumo: Para delinear uma visão de conjunto sobre o pensamento de Horkheimer nos 1940, procura-se defender duas teses: primeiramente, trata-se de apoiar a ideia de que a crítica da razão, que marca esse período, se deve em última instância a uma crítica endereçada à esquerda, que Horkheimer desenvolve no ensaio "Estado autoritário". A segunda tese afirma, por sua vez, que a crítica da razão aponta para dois caminhos diferentes na obra de Horkheimer, traçados em dois livros quase simultâneos: Dialética do esclarecimento, em parceira com Th. W. Adorno, e Eclipse da razão. A primeira obra representa uma via que pode ser chamada de "nietzschiana", caracterizada pela identidade entre razão e dominação. A segunda obra, por sua vez, mostra uma via "kantiana", a qual deve lidar na modernidade com o conflito entre a razão subjetiva e a razão objetiva.
\end{abstract}

Palavras-chave: esquerda; razão; Teoria Crítica; capitalismo de Estado; dominação; Esclarecimento.

\begin{abstract}
In order to delineate an overview of Horkheimer's thought in the 1940s, two theses are defended: firstly, it is intended to support the idea that the critique of reason, which marks this period, is ultimately due to a critique of the left, as developed in the essay "Authoritarian State". The second thesis, in turn, states that the critique of reason takes two paths in Horkheimer's work, in two almost simultaneous books: Dialectic of Enlightenment, in partnership with Th. W. Adorno, and Eclipse of Reason. The first work represents a way that can be called "Nietzschean", characterized by the identity between reason and domination. The second work, in turn, shows a "Kantian" way, which must deal in modernity with the conflict between subjective reason and objective reason.
\end{abstract}

Keywords: left; reason; Critical Theory; State Capitalism; domination; Enlightenment.

DOI: http://dx.doi.org/10.11606/issn.2318-9800.v22i2p93-109

$\mathrm{Na}$ literatura de comentário sobre Max Horkheimer parece haver um sólido consenso a respeito da centralidade que a crítica da razão adquire no seu pensamento desde o início dos anos 1940. Atada ao tema “razão", a Teoria Crítica de Horkheimer teria se recolhido enfim ao terreno próprio da filosofia, teria sofrido uma espécie de

* Agradeço a todas e todos colegas pelas questões e sugestões por ocasião do Colóquio Horkheimer na Universidade de São Paulo, e do Colóquio “Lumières et Modernité”, na Universidade de Rennes. Faço um agradecimento especial a Simone Fernandes pela revisão e pelas sugestões bibliográficas para a versão definitiva desse estudo. 
“refilosificação”, para usar uma expressão cunhada por Helmut Dubiel (1978, p.125). Mais do que nunca, ela se torna uma atividade filosófica e não tanto uma atividade de ciência social.

Em correspondência com isso, diversos autores, como Jürgen Habermas, sugerem que ocorre no pensamento de Horkheimer dessa época, apesar do envolvimento com os estudos empíricos articulados, um abandono teórico do programa de materialismo interdisciplinar que o próprio Horkheimer havia criado ao assumir a direção do Instituto de Pesquisa Social no começo da década de 1930 (Habermas, 1987, pp.516 ss.; 2000, pp.168 ss.). ${ }^{1}$ Juntamente com isso, o modo de pensar mais historica e socialmente orientado, o qual caracterizava o programa, teria se alterado drasticamente (Abromeit, 2011, pp.410 ss.).

No programa do materialismo interdisciplinar esboçado por Horkheimer, a filosofia aparecia como uma “intenção teórica orientada ao universal”, capaz de "dar impulso animador às pesquisas particulares e ser aberta o suficiente para se deixar impressionar e transformar-se pelo progresso dos estudos concretos" (Horkheimer, 1931, p.29). À filosofia caberia o papel de integrar as pesquisas especializadas entre si, superando seu caráter unilateral, uma vez que o falso na teoria científica tradicional se concentra antes de tudo na organização metodológica que divide a totalidade da práxis social (Horkheimer, 1937, p.254). Agora, nos anos 1940, as ciências sociais parecem ser meras coadjuvantes de uma tarefa que já tem uma longa história na filosofia: a crítica de seu tema máximo, a razão.

De modo algum isso significaria dizer que a crítica da razão não havia desempenhado um papel de relevo nos estudos anteriores de Horkheimer, sobretudo aqueles ligados à autoridade, na medida em que esta se reveste de uma forma racional. Certamente, os processos de racionalização social já eram, de um modo ou de outro, o alvo de muitas pesquisas no Instituto de Pesquisa Social nos anos 1930. A questão decisiva é saber por que o próprio conceito de razão ganhou a centralidade que passou a ter, em Horkheimer, ao longo dos anos 1940.

A respeito desse ponto, pode-se dizer que a literatura interpretativa considera de maneira geral que a crítica da razão se deve sobretudo ao diagnóstico de época segundo o qual a dominação fascista seria a dimensão propriamente política do predomínio da razão instrumental desde a era moderna, como o resultado mais visível da cultura burguesa. A civilização burguesa e seus valores, a ciência, o progresso técnico, em suma, sua concepção de razão contém os elementos que conduzem à barbárie fascista. Não é possível negar a pertinência dessa consideração, uma vez que vários textos de Horkheimer mostram como as estruturas sociais burguesas e

\footnotetext{
1 Para uma visão contrária, que insiste antes em um novo rearranjo interdisciplinar a partir de uma transformação da psicanálise, cf. Marin, Nobre, 2012. Sobre os estudos empíricos desenvolvidos na época de exílio nos Estados Unidos, voltados sobretudo para a pesquisa sobre o antissemitismo, e suas mediações "problemáticas" com a teoria e a práxis política, cf. Jay, 2008, cap. VII e VIII.
} 
capitalistas criam formas de dominação extremamente autoritárias, por exemplo, na familía e na educação (cf. Horkheimer, 1936a/1988; Genel, 2013). Somam-se a isso as próprias formulações dos anos 1940 que declaram a associação entre civilização burguesa (ou moderna) e a autoaniquilação da razão.

Porém, vista de outra perspectiva, essa consideração da literatura de comentário supõe logicamente que Horkheimer possuiria uma larga confiança no potencial de racionalidade da cultura burguesa para que ele considerasse afinal sua transformação fascista como o principal motivo da revelância cada vez maior do tema da razão. Em direção contrária a essa suposição, pode-se lembrar que seu estudo sobre o "Egoísmo e movimento de libertação" já realiza uma crítica da cultura burguesa que, mesmo se atendo ao conteúdo racional imanente a ela, aos conceitos de autonomia e de justiça, não deixa de sugerir diversas vezes que os fenômenos cultural e socialmente reprimidos, como o próprio egoísmo, o prazer sexual e, de modo geral, o gozo material, representam muito mais um potencial de negatividade do que os ideais da cultura burguesa sublimada, da "interiorização". 2

Parece-me mais sensato supor, assim, que é a decepção sistemática com as forças opostas à cultura burguesa e ao capitalismo o principal fator para explicar as transformações no seu pensamento, ou seja, a decepção com as forças ditas progressistas, em princípio não burguesas ou anticapitalistas. Se Horkheimer demonstra uma atenção constante ao processo de dominação em que os sujeitos individuais passam a desejar a própria sujeição, a relação de autoridade, como sublinha Katia Genel (Genel, 2013, pp.17ss.), é somente quando a oposição organizada, coletiva, já existente, torna-se um elemento do poder que se pode compreender a guinada em direção à crítica da razão. Sem dúvida, Horkheimer jamais deixa de lado a análise do fascismo e de sua relação interna com a cultura burguesa liberal e com o capitalismo de modo geral, como testemunha de maneira enfática o ensaio sobre "Os judeus e a Europa". ${ }^{3}$ Porém a guinada para a crítica da razão só pode ser explicada, em última instância, por meio de uma atenção concentrada sobre a relação entre a

\footnotetext{
2 "A crítica ao egoísmo", escreve Horkheimer, "se ajusta melhor ao sistema da realidade egoísta do que sua defesa aberta, pois ele se baseia em grau crescente na denegação de seu caráter; a vigência pública da regra seria ao mesmo tempo também seu ocaso" (Horkheimer, 1936b, p.169). Por outro lado, no ensaio sobre "Montaigne e a função do ceticismo", ao comentar a atitude de desapreço do filósofo francês pela religião e pela ciência, por mor da estabilidade política, Horkheimer também detecta no ceticismo moderno um traço peculiar da cultura burguesa: "Na atitude de Montaigne se expressam traços importantes do espírito burguês. (...) A tendência a subordinar a verdade ao poder não emergiu pela primeira vez com o fascismo; profundamente enraizado na situação econômica da burguesia tanto quanto os traços liberais, o irracionalismo atravessa a história inteira dos tempos modernos, restringindo seu conceito de razão" (Horkheimer, 1938, p.15). Tanto na recusa do egoísmo quanto na atitude cética moderna, Horkheimer vê a operação de formas enraizadas de resignação e assujeitamento que são determinantes da cultura burguesa.

3 "Ninguém pode desejar que os emigrantes, que testemunham por si mesmos o fascismo, apresentem para o mundo um espelho justamente ali onde ele lhes concede ainda asilo. Mas quem não quer falar de capitalismo deveria se calar também sobre o fascismo" (Horkheimer, 1939, p.115).
} 
crítica da razão enquanto tal e a crítica destinada às correntes da esquerda de sua época. Não se trata somente da desilução com as expectativas revolucionárias, como se costuma frisar em diferentes medidas. A decepção de que se trata aqui é de tal ordem que o discernimento racional no interior da explicação sobre a perda do sujeito revolucionário se volta para si mesmo. A forma racional da oposição de esquerda passa a ser o elemento explicativo fundamental.

Além disso, considero que a relação tensa entre a crítica à esquerda e a crítica à razão - que são simultaneamente uma crítica de esquerda e uma crítica da razão sobre si mesma - tem de ser colocada programaticamente na base de explicação de outro ponto sobre o pensamento de Horkheimer nos anos quarenta que boa parte da literatura de comentário tem ignorado. Pois ela também tem dado pouca atenção às diferenças ou oscilações que marcam a realização da crítica da razão nas duas principais obras de Horkheimer desse período: Eclipse da razão e Dialética do esclarecimento. Quanto a isso, a interpretação de Habermas segundo a qual a primeira "apenas concentra o conteúdo sistemático" da segunda (Habermas, 1987, p.463) é também representativa dessa justaposição (cf. ainda Wiggerhaus, 1988, p.344; Petry, 2013). Para isso contribuiram sem dúvida declarações do próprio Horkheimer que enfatizam a continuidade entre as obras, como o prefácio de Eclipse da razão (1947/2004, p.vi).

Pretendo dar relevo a esses dois pontos: por um lado, a crítica à esquerda como momento de inflexão rumo à crítica da razão, e, por outro lado, os caminhos diferentes dessa guinada. Para tanto, vou defender primeiramente a tese segundo a qual a guinada de Horkheimer em direção à crítica da razão se deve fundamentalmente ao fato de que praticamente todas as variantes de esquerda com força política e social representam para ele a afirmação de uma forma de dominação autoritária - e nesse sentido se identificam com aquilo que combatem. Essa conexão se apoia principalmente em dois textos quase simultâneos de Horkheimer: "O fim da razão" e o "Estado autoritário", ambos do começo dos anos 1940. O "Estado autoritário" deve ser entendido como o diagnóstico político de Horkheimer, um diagnóstico que é formulado de tal modo que o processo de modernização como racionalização tem de ser a chave de por que os movimentos de esquerda mal se diferenciam das forças conservadoras e regressivas das sociedades capitalistas da época. Esse diagnóstico é desdobrado um pouco mais tarde no ensaio inacabado "Sobre a sociologia das relações de classe", de 1943, dedicado à transformação das relações de classes em uma luta de todos os grupos sociais por uma parcela na dominação e na riqueza, no mais das vezes por meio da extorsão.

Minha segunda tese se volta às diferenças entre os caminhos que Horkheimer trilha a partir do diagnóstico de que todas as forças de emancipação teriam se ligado a formas de autoritarismo. Essas diferenças já estão presentes no ensaio sobre o "Fim 
da razão", que na versão alemã passa a se chamar "Razão e autoconservação", e ganham contornos um pouco mais nítidos naquilo que separa as obras Eclipse da razão e Dialética do esclarecimento, publicadas ambas em 1947. A última tem sua versão quase definitiva em 1944, mesmo ano em que Horkheimer profere as conferências que servirão de base para a primeira. ${ }^{4}$

Correndo o risco de simplificar muito as coisas, e deixando de lado muitas continuidades entre os dois livros, proponho que a via de Eclipse da razão possa se chamar uma via "kantiana". Nesse caso, a crítica da razão se equilibra em dois conceitos concorrentes de razão, um conceito de razão subjetiva e um conceito de razão objetiva. Na crítica dessas duas formas de razão em disputa, Horkheimer se apoia tacitamente em um conceito de crítica reflexiva que abre uma dimensão da razão não redutível a esses dois conceitos em disputa.

Por sua vez, a Dialética do esclarecimento, escrita com Theodor W. Adorno, segue uma trajetória distinta. A crítica da razão segue a linha de uma antropologização da razão que não contrapõe formas distintas de racionalidade, mas antes demonstra a identidade profunda entre razão e dominação, entre razão e mito. Aqui transparece uma via, por assim dizer, "nietzschiana" de crítica da razão, a qual tem de assumir explicitamente uma forma aporética, como os autores expressam no prefácio do livro.

Começo com a crítica à esquerda, sobre a qual é preciso enfatizar mais uma vez seu posicionamento à esquerda. Essa crítica só é compreensível no seu essencial quando inserida no diagnóstico de época desenvolvido dos anos 1940. Isso pressupõe por sua vez também uma variação em relação ao diagnóstico dos anos 1930, consolidado em “Teoria crítica e teoria tradicional” (1937). Já nesse texto, fundamental para a compreensão do que significa afinal “Teoria Crítica”, transparece uma crítica aos partidos e movimentos operários; no entanto, o tom prevalescente é antes dado pelas novas formas de dominação de que o fascismo se vale contra as forças progressistas do proletariado.

Em "Teoria crítica e teoria tradicional”, Horkheimer realiza a tarefa de desenvolver, apoiando-se em Marx, o conceito de teoria crítica ao mesmo em que se afasta consideravelemente dos prognósticos marxistas sobre a evolução do capitalismo.

Segundo Horkheimer, Marx constrói sua teoria crítica do capitalismo tendo em vista as tendências objetivas que conduzem à superação do capitalismo, ou seja, à sociedade emancipada, verdadeiramente racional. Essas tendências se encontram,

4 Sobre os contextos de redação e publicação das duas obras, cf. Schmidt, 2007. 
de um lado, no desenvolvimento das forças produtivas, isto é, da ciência, da técnica e da organização racional do trabalho, de outro, na formação social e política do proletariado.

O proletariado, devido à sua situação no processo de produção, pode experimentar por seu trabalho tanto os avanços técnicos no domínio da natureza como a renovação constante das relações caducas de produção. Ao mesmo tempo, o próprio sistema de mercado, entregue a si mesmo, leva ao agravamento das oposições sociais, e, com isso, à possibilidade de revolucionamento da sociedade como um todo. Em suma, o capitalismo criaria por si mesmo as forças que o destruiriam. Ele cria as forças produtivas por meio das quais o proletariado se forma, e por meio das quais o sistema entre em colapso. Ele cria o próprio sujeito revolucionário que o derrubará ao transformar boa parte da população na massa proletariada, cada vez mais instruída pelas forças produtivas e cada vez mais pauperizada.

Para Horkheimer, essas tendências caracterizam o "capitalismo liberal", como ele se desenrolou ao longo do século XIX. No entanto, elas não se aplicam mais ao "capitalismo monopolista" tal como ele se desdobra mais ou menos desde o final do século XIX (cf. Horkheimer, 1937, pp.284 ss.).

No "capitalismo monopolista", possibilitado por uma enorme concentração de capital, a figura do grande proprietário privado, o burguês tradicional, é substituída no comando da economia pelos diretores executivos dos grandes conglomerados, os quais dominam setores inteiros das economias nacionais. Com a redução do número dos que detêm efetivamente o poder, aumenta, por sua vez, a possibilidade de elaborar conscientemente novas ideologias e métodos de controle social. Esses métodos são disponibilizados pelo avanço das técnicas de comunicação de massa como o rádio e o cinema, mas também pelas próprias ciências humanas, como a sociologia e a psicologia. Os mecanimos de dominação de massa se tornam cada vez mais conscientes de si mesmos. A dominação burocrática é altamente cínica, na medida em que não há nenhuma crença a respeito da pretensão de validade das ideologias artificialmente criadas (Horkheimer, 1937, p.286).

Além disso, as afirmações marxistas tradicionais sobre a contínua pauperização dos trabalhadores são refutadas por uma integração cada vez maior deles à sociedade capitalista e por uma diferenciação cada vez maior no interior da classe. A melhora no padrão de consumo de uma parte significativa dessa camada impossibilita uma identificação imediata e consistente entre interesses pessoais e de classe. Mais grave ainda, parcelas igualmente significativas do proletariado aderem às correntes políticas mais autoritárias e mesmo fascistas, como já era o caso na Alemanha e na Itália.

A teoria crítica já não pode sem mais considerar que a situação do proletariado na sociedade moderna acarreta por si só uma compreensão verdadeira 
do desenvolvimento da sociedade, como já foi o caso em Lukács, ${ }^{5}$ e um potencial inequívoco de emancipação. Dito de outro modo, altera-se profundamente a relação entre teoria e práxis. A teoria crítica precisa manter-se, de agora em diante, em total independência em relação aos grupos e às classes sociais. A consciência crítica de qualquer uma delas pode se corromper por mais que sua posição na sociedade a facultasse para a verdade. Assim, Horkheimer escreve que "antes da reviravolta histórica universal a verdade pode estar em unidades numericamente pequenas" (Horkheimer, 1937, p.291), "refugiada em pequenos grupos dignos de admiração, que, dizimados pelo terror, têm pouco tempo para aguçar a teoria” (idem, p.288).

No entanto, se em 1937 Horkheimer aventa ainda a possibilidade de uma "reviravolta histórica universal", nos anos subsequentes essa perspectiva parece totalmente liquidada. No ensaio de 1940 sobre o "Estado autoritário", Horkheimer já não fala mais de capitalismo monopolista, mas antes de "capitalismo de Estado", utilizando francamente o termo empregado por seu amigo Friedrich Pollock, que um ano depois publicaria seu texto mais conhecido: "Capitalismo de Estado, suas possibilidades e suas limitações”.

Nas palavras de Horkheimer, “o capitalismo de Estado é o Estado autoritário do presente" (1940/1987). Embora Horkheimer considere que o capitalismo de Estado já tivesse sido previsto por Engels em sua fase tardia, o vocabulário e as consequências políticas são visivelmente extraídos da análise de Pollock. A começar pela ênfase no diagnóstico segundo o qual o capitalismo não mais entrará em colapso por razões econômicas. Ele assume a tese forte de Pollock, de acordo com a qual o mercado perde inteiramente as funções de produção e distribuição de riquezas, transferindo-as para o Estado. Com isso, e de um modo que causou longa polêmica na época, Pollock afirma que a economia política perdeu seu objeto (cf. Rugitsky, 2008; Nobre, 2008; Marramao, 1975; Jay, 2008; Postone, Brick, 1993). Para entender o capitalismo de Estado, deve-se antes entender como se articulam os novos grupos dominantes, a burocracia empresarial, a burocracia estatal e os grandes líderes de partidos políticos vitoriosos. ${ }^{6}$

É verdade, contudo, que há também uma diferença de vulto entre a abordagem de Horkheimer e a de Pollock. Para este, o capitalismo de Estado pode adotar duas formas, uma totalitária e uma democrática (Pollock, 1941, pp.201 ss.; Nobre, 1998). $\mathrm{Na}$ forma totalitária, o Estado é um instrumento de poder a serviço desses novos grupos que suplantaram a burguesia industrial tradicional. Na forma democrática,

\footnotetext{
5 Sobre a relação entre o texto de Horkheimer e História e consciência de classe, de Lukács, cf. Habermas, 1987, Nobre, 1996.

6 No prefácio para o número da Zeitschrift que publica o texto de Pollock, Horkheimer acrescenta também os líderes da propaganda e do exército. Cf. 1941b, pp.195-196. No ensaio "Sobre a sociologia das relações de classe", as lideranças das organizações operárias também são arroladas como nova elite, ao mesmo tempo em aliança e em disputa com os demais grupos dirigentes (cf. Horkheimer, 1943).
} 
haveria, segundo Pollock, instituições capazes de limitar o uso do Estado por esses novos grupos.

Nas duas formas ocorre um deslocamento de todos os problemas econômicos de peso para a esfera política; o que muda é o quadro institucional da política em um caso e em outro. Ou melhor, só na forma democrática se pode falar a rigor de um quadro institucional, pois na totalitária opera o uso contínuo da violência. Nas palavras de Pollock, "todo aquele que não faz parte do grupo dominante é mero objeto de dominação" (Pollock, 1941, p.201).

Ora, no seu texto, como indica o título, Horkheimer só se interessa pela forma totalitária. Isso é um motivo para supor que a forma de um capitalismo administrado pela burocracia estatal, em última instância, o controle burocrático da sociedade, em todos os seus poros, será para ele a realidade inelutável do mundo, mesmo com a derrota do nazismo e do fascismo. E isso porque não só as forças da direita, mas também as forças da esquerda caminham para esse sentido. Assim, em seu ensaio, Horkheimer procura entender os mecanismos que levam não à derrocada da burguesia e do mercado, como é o caso do texto de Pollock, mas antes à derrocada do próprio proletariado, em seu contínuo processo de adaptação à realidade dada:

Que o capitalismo pode sobreviver à economia de mercado é algo que se anunciou há muito tempo no destino das organizações do proletariado. (...) As grandes organizações promoveram uma ideia de socialização [Vergesellschaftung] que mal se distinguia da estatização, da nacionalização ou da socialização [Sozialisierung] no interior do capitalismo de Estado. A imagem revolucionária de emancipação continuou a viver somente nas calúnias dos contrarrevolucionários. (...) Mesmo a utopia foi formulada segundo regras preventivas. Os seres humanos foram representados como objetos, se necessário, como seus próprios objetos (Horkheimer, 1940, p.295).

Para Horkheimer, aqui não importa tanto mostrar o quão pouco o socialismo de Estado, o "estatismo integral” levado a cabo na União Soviética, se diferencia do capitalismo de Estado totalitário, o quão pouco variam as formas de Estado autoritário. O mais decisivo é o processo pelo qual todas as forças negativas e progressistas se ajustam aos mecanismos de opressão. Por isso ele não se refere apenas ao estalinismo. A crítica às organizações políticas e sindicais do proletariado vai desde as formas socialdemocratas até as bolcheviques, desde as vias reformistas até as revolucionárias. De modo geral, nenhuma variante de esquerda com peso político na época é poupada. Ao longo do ensaio se acumulam frases como: "O movimento revolucionário espelha negativamente a situação que ele ataca” (Horkheimer, 1940, pp.297-298), ou “O Estado autoritário tem de temer os partidos de massa adversários somente como concorrentes. Eles não tocam no princípio” (idem, p.302).

Ora, o que é comum a todas essas tendências de esquerda, e entre estas e as formas autoritárias de direita, é o princípio de racionalização, a organização burocrática racional da dominação. É nesse aspecto que a racionalização promovida 
pelas forças produtivas se torna chave para a compreensão do processo de aniquilação dos potenciais de emancipação. Quanto mais as forças de oposição se organizam segundo os critérios da racionalização, o "espírito da administração", tanto mais elas se transformam em forças de afirmação do status quo. Assim, nas poucas projeções utópicas que restaram a sociedade emancipada, socialista, é descrita em termos de racionalidade administrativa. A seguinte passagem também dá testemunho do amplo arco de referências de esquerda que tem em vista Horkheimer, mencionando a Alemanha pré-nazista e a organização sindical nas democracias ocidentais:

O que quer prosperar sob a dominação se encontra sob o risco de reproduzir a dominação. Na medida em que a oposição proletária na República de Weimar não declinou como seita, ela sucumbiu também ao espírito da administração (...). Nas democracias remanescentes, os dirigentes das grandes organizações operárias se encontram já hoje com seus membros em uma relação análoga aos executivos no estatismo integral com a sociedade inteira: mantêm a massa de que cuidam em estrita disciplina, se fecham contra a afluência descontrolada, toleram a espontaneidade apenas como resultado de seu próprio poder (Horkheimer, 1940, p.296).

Por outro lado, a passagem sugere uma certa reminiscência da simpatia que Horkheimer nutria por Rosa Luxemburg, dada a conhecida crítica que ela sempre endereçou à burocratização dos partidos operários, em especial à teoria leninista sobre a organização do partido revolucionário, acompanhada da correspondente defesa da espontaneidade das massas (cf. Luxemburg, 2011). Esse vínculo com a vertente luxemburguista é reforçado ainda mais no único momento em que Horkheimer delineia mais concretamente o contraponto às tendências majoritárias: “A concepção teórica que, de acordo com os primeiros combatentes da nova sociedade, deve apontar o caminho, o sistema de conselhos, surgiu da práxis. Ele remonta a 1871, a 1905 e a outros acontecimentos. A transformação tem uma tradição de cuja continuidade depende a teoria" (Horkheimer, 1940, p.304; cf. Jay, 2008, p.211). Porém é justamente essa continuidade que parece totalmente perdida no momento em que Horkheimer desenvolve seu diagnóstico político. As posições predominantes à esquerda, socialdemocratas, trabalhistas e bolcheviques, são absorvidas cada vez mais pelas injunções da racionalização técnica e burocrática que elas promoveram.

No ensaio "Sobre a sociologia das relações de classe", o qual já reflete diversos passos teóricos próprios de Dialética do esclarecimento e Eclipse da razão, a visão de Horkheimer sobre as organizações operárias se torna ainda mais amarga. Elas teriam se tornado meios de disputa entre os mais diversos grupos dirigentes pela partilha da dominação social e refletem em si mesmas e em cada membro a racionalidade técnica e pragmática do todo. Para uma teoria das relações de classes, Horkheimer desenvolve aí um conceito de sistema de extorsões (racket) como meio privilegiado de influência dos diversos grupos dirigentes uns sobre os outros - além de ser forma de sociabilidade em geral - como se todas as organizações políticas tivessem se 
tornado organizações de gângsteres, ao mesmo tempo em que são cada vez mais operacionalizáveis em termos de racionalidade técnica (Horkheimer, 1943; Stirk, 1992, p.140ss., Genel, 2013, pp.278 ss.).

Ora, se é assim, podemos compreender porque a razão se torna o problema central para a teoria crítica da sociedade. Somente quando as forças de oposição, somente quando a "negação determinada", para se valer da expressão chave da dialética hegeliana, se vê contaminada na raiz, qualquer expectativa sobre a razão tem que se frustrar e alimentar uma suspeita sistemática sobre si mesma. 0 destino da esquerda, que um dia quis uma sociedade "racional", faz do "racional" a primeira fonte de suspeita.

No ensaio "O fim da razão", publicado um ano depois da escrita de "Estado autoritário", é efetuado o passo definitivo rumo à crítica da razão. ${ }^{7}$ Ele pode ser visto como o esboço de um programa de investigação que marca a trajetória de Horkheimer nos anos 1940. Nele, Horkheimer busca estabelecer a íntima conexão entre razão e o princípio de autoconservação do Eu, entre racionalidade e dominação da natureza, entre racionalidade e técnica.

Ao mesmo tempo, esse ensaio testemunha duas estratégias distintas de lidar com a crítica da razão. Ora, ele enfatiza o laço antropologicamente enraizado entre razão e dominação, ora ele atenta para o caráter processual e histórico do fim da razão, da revelação da razão como irrazão. De um lado, o fundamento antropológico que liga razão e autoconservação. De outro lado, o processo em que a racionalidade é predominantemente burguesa e nesse sentido historicizada. Muitas vezes, estas estratégias se entrelaçam e mal se distinguem. Mas os argumentos de que se vale Horkheimer em ambas não se equivalem e contêm potenciais distintos.

Essas diferenças se acentuam pelo fato de Horkheimer ter seguido as duas trilhas em obras distintas, Eclipse da razão e Dialética do esclarecimento, esta última escrita com Adorno. A diferença mais visível diz respeito sobretudo às coordenadas históricas da crítica dialética da razão. Em Eclipse da razão, Horkheimer parte de uma oposição entre duas concepções estruturais distintas e, ao mesmo tempo, historicamente situadas de razão.

Em um caso, a racionalidade está umbilicalmente ligada ao interesse subjetivo pela autoconservação e às capacidades subjetivas de conhecer as coisas e

\footnotetext{
7 Cabe lembrar que a versão alemã, "Vernunft und Selbsterhaltung" ("Razão e autoconservação") foi publicada junto com "Estado Autoritário", em um volume destinado à memória de Walter Benjamin, cuja circulação, em 1942, permaneceu restrita ao âmbito do Instituto. Essa circunstância leva a supor tanto a pouca disposição de Horkheimer em estender publicamente sua crítica à esquerda como também o vínculo íntimo entre os dois escritos.
} 
de modificá-las conforme um cálculo de eficácia dos meios. Horkheimer caracteriza essa racionalidade como razão subjetiva, formal e instrumental, por oposição à razão objetiva, substantiva e contemplativa. Pois esta razão objetiva se define por retirar seus critérios e princípios não das faculdades do sujeito individual que conhece e age, mas da realidade conhecida e modificada por ele.

Segundo Horkheimer, nas doutrinas filosóficas em que se consolida a razão objetiva, desde a Antiguidade até o começo da era moderna, a inteligência do indivíduo não estaria voltada unicamente para a autoconservação, mas para o reconhecimento da razão inscrita objetivamente no cosmos, na natureza, na totalidade do existente. A razão se encontra no mundo, do qual o indivíduo é um momento. Por sua vez, para a concepção subjetiva e instrumental, a racionalidade só se verifica nas capacidades do sujeito, que toma tudo o que está à sua volta como objetos a serem conhecidos e manipulados. Até mesmo a própria subjetividade é um objeto de conhecimento e ação para o sujeito. Ele conhece sua própria natureza instintiva para reprimi-la convenientemente.

Como dito, a oposição entre as duas concepções de razão é situada historicamente. Isso significa que, nas sociedades modernas, essa oposição deixou de ser inteiramente atual, já que a razão subjetiva acabou predominando depois de um longo processo de decomposição da razão objetiva. Se até o final do século XVII as diversas metafísicas buscavam ainda uma doutrina do homem e da natureza capaz de unificar o indivíduo e o todo, segue-se depois disso a impossibilidade histórico-social de tal unificação. A imposição da racionalidade formal e instrumental, meramente centrada no sujeito do conhecimento e da ação, se realiza a partir da crise insolúvel da metafísica. Toda elucidação metafísica do mundo passa a ser vista, desde o século XVIII, como sinônimo de mitologia e superstição. Embora a relação entre razão e autoconservação seja apontada também nos primórdios do processo de hominização, o acento crítico recai na modernidade e na sociedade industrializada.

Por outro lado, apesar da vitória histórica da razão subjetiva, a razão objetiva persiste em reaparecer também na modernidade, no mais das vezes como panaceia que apenas confirma a vitória da inimiga. Mas ao mesmo tempo essa recorrência demonstra que a antinomia se mantém também na modernidade. 0 fato de que haja pretensões, ainda que historicamente caducas, de uma racionalidade objetiva, demonstra que todo conceito de razão não pode prescindir inteiramente de uma pretensão metafísica. Assim, Horkheimer parece realizar uma história da razão baseada em estruturas resilientes.

A semelhança desse empreendimento filosófico com Kant é ressaltada pelo próprio Horkheimer:

A tarefa da filosofia não é jogar teimosamente uma contra a outra, mas promover uma crítica mútua, e assim, se possível, preparar na esfera intelectual a reconciliação 
das duas na realidade. A máxima de Kant, "o caminho crítico somente está ainda aberto", que se referia ao conflito entre a razão objetiva do dogmatismo racionalista e o raciocínio subjetivo do empirismo inglês, se aplica ainda com mais pertinência na situação presente (Horkheimer, 1947/2004, p.118).

A adoção da máxima de Kant demonstra que, para Horkheimer, a crítica da razão se instala em uma dimensão reflexiva, capaz de buscar um equilíbrio e uma unidade entre as duas concepções opostas de racionalidade. A partir dessa instância reflexiva, a própria separação entre as duas concepções se apresenta como ilusória, mas, de acordo com Horkheimer, uma "aparência necessária”, para se valer de uma expressão cara a Kant e a Marx (Horkheimer, 1947/2004, p.118). Ao mesmo tempo, essa linha de pensamento se encontra longe de ser desenvolvida ao longo do livro. Certamente, Kant ocupa uma posição única na reconstrução do século XVIII, visto que ele faz, assim sugere Horkheimer, uma crítica da razão subjetiva sem perder de vista a universalidade objetiva das estruturas do conhecimento e da ação (cf. Horkheimer, 1947/2004, p.29). Porém as referências mais precisas de como se pode desenvolver a via kantiana no contexto apresentado são bastante esparsas.

O mesmo não ocorre com a Dialética do esclarecimento, cuja ideia nuclear sobre a relação entre razão e dominação encontra vários níveis de desenvolvimento. Mas o que é chamativo para o leitor de Eclipse é o fato de a oposição entre razão subjetiva e razão objetiva não desempenhar nenhum papel relevante. Embora muitas ideias se repitam, a articulação da crítica da razão segue uma estratégia bem distinta na Dialética.

Em parte alguma deste livro essa estratégia é ilustrada de maneira mais pregnante, no meu ponto de vista, do que nas recorrentes referências ao mito de Ulisses e as sereias. O episódio de Ulisses e as sereias é abordado, na Dialética do esclarecimento, para ilustrar as relações de autoconservação e automutilação como constitutivas do indivíduo e do ego. Ulisses pretende ouvir o canto irresistível das sereias, que enlouquecem os homens a ponto de eles se jogarem ao mar. Então ordena aos seus comandados que tapem os ouvidos com cera e o amarrem ao mastro. Tomado pelo desejo ao ouvir o canto, ele grita desesperadamente para que o desamarrem, mas seus companheiros não podem escutá-lo.

Ulisses sacrifica sua natureza instintiva, mutilando-a, ao mesmo tempo em que mutila de certo modo os seus comandados. 0 ego se forma e se preserva, dessa maneira, como uma renúncia a si mesmo, como um autossacrifício. A dominação das forças naturais supõe uma dominação entre os homens e, ao mesmo tempo, o domínio de cada indivíduo sobre sua natureza pulsional. Dessa maneira, já está inscrita na gênese do indivíduo e do ego o paradoxo da razão instrumental. Se sua finalidade é preservar o indivíduo, ela o realiza por um sacrifício do indivíduo, por uma constante repressão de seus impulsos. A vida a ser conservada tem de ser sempre uma vida 
danificada.

Não se trata aqui, portanto, de uma razão subjetiva que veio a imperar na civilização burguesa. Na Dialética do esclarecimento, não há dois conceitos contraditórios de razão em jogo. Mesmo se a metafísica ainda é vista como até certo ponto resistente à instrumentalização subjetiva, tudo o que se distingue do processo de esclarecimento racional passa a ser considerado como uma espécie de cúmplice desse mesmo processo. E também o inverso: tudo que seria antiesclarecimento traz consigo algo de seu oposto. Assim, não só a metafísica está envolvida no processo de esclarecimento, como também o mito, historicamente anterior à metafísica, já apresenta em si mesmo algo de esclarecimento, e este, por sua vez, tem como destino o retorno ao mito, como é expresso nas duas teses defendidas pelos autores: "o mito já é esclarecimento e o esclarecimento reverte em mitologia” (Horkheimer, Adorno, 1947, p.21).

Antes de tudo, convém observar duas coisas sobre essas teses. Primeiramente, o que reúne mito e esclarecimento é o propósito comum, consciente ou inconsciente, exigido de fora ou internalizado, de dominar a natureza. Desde o início Horkheimer e Adorno evidenciam que o esclarecimento é antes de tudo um processo de “desencantamento do mundo" (Horkheimer, Adorno, 1947, p.25), uma racionalização no sentido de Weber, cujo objetivo primeiro é o domínio sobre a natureza e sobre os homens. Por sua vez, o mito não é visto apenas como um modo de narrar a origem, mas também um modo de fixar e ludibriar a natureza.

Em segundo lugar, a reversão à mitologia não deve ser entendida como um retorno ao aspecto narrativo do mito, mas unicamente o reinício da autonomização das forças criadas pelo homem em relação ao próprio homem. Na civilização racionalizada, os processos sociais se apresentam aos indivíduos como os processos naturais nas comunidades primitivas: como forças alheias a eles.

Portanto, a dialética da razão subjetiva que Horkheimer arma em Eclipse da razão é, por assim dizer, estendida até o mito, de modo que fica suspensa a oposição entre duas formas distintas de racionalidade. 0 que se quer enfatizar não é a contradição entre dois modos de explicar e lidar com o mundo, mas a sua mútua compenetração.

O traço nietzschiano desse modelo de dialética é acentuado pelos próprios autores, pois é a Nietzsche que eles atribuem a "impiedosa doutrina da identidade entre dominação e razão" (Horkheimer, Adorno, 1947, pp.142-143). Não é o caso aqui retomar a comparação que Habermas faz entre a Dialética do esclarecimento e a Genealogia da moral (cf. Habermas, 2000, pp.171 ss.). Mesmo porque é preciso acentuar também que esse elemento nietzschiano é introduzido no interior de um modelo de Teoria Crítica que, em todo caso, continua a se afirmar como tal. Porém, o interesse pela emancipação que caracteriza a Teoria Crítica tem que se enredar na 
autocontradição assumida por Horkheimer e Adorno no prefácio da obra.

Nesse contexto, a autocontradição da Teoria Crítica se deve ao fato de que as forças que impelem à barbárie não se opõem mas antes se confundem com a racionalidade ou derivam dela. E como o pensamento crítico não pode simplesmente dispensar a razão, porque tanto se estrutura conceitualmente quanto recorre sempre às ideias racionais de liberdade, verdade e justiça, ela vê em si mesma o elo com aquilo que crítica. Daí a famosa formulação da aporia da Teoria Crítica:

A aporia com que nos deparamos em nosso trabalho revela-se assim como o primeiro objeto que nós tínhamos de investigar: a autodestruição do esclarecimento. Não alimentamos dúvida nenhuma - e nisso reside nosso petitio principii - de que a liberdade na sociedade é inseparável do pensamento esclarecedor. Porém, cremos ter reconhecido com igual evidência que o conceito justamente desse pensamento, não menos que as formas históricas concretas, as instituições da sociedade com as quais está entrelaçado, já contêm o germe para a regressão que hoje ocorre em toda parte (Horkheimer, Adorno, 1947, p.18).

Junto com o esclarecimento, a Teoria Crítica se encontra em contradição. Ela não pode abandonar a ideia de razão, que propõe o esclarecimento sobre os processos naturais e sociais, e ao mesmo tempo não pode deixar de reconhecer que é já nessa ideia de razão, "não menos" do que nas instituições fundadas sobre ela, que se encontra o germe da regressão. A possibilidade da crítica é contraditada pela lógica conceitual da crítica. Com isso, certamente Horkheimer e Adorno pressupõem um conceito de razão que se funda com as intenções primeiras da Teoria Crítica, e ao mesmo tempo cortam explicitamente as vias que poderiam ao menos esboçar sua configuração estrutural.

Para o Horkheimer de Eclipse da razão, o caminho da crítica é o único que está aberto. Para o Horkheimer da Dialética do esclarecimento, esse caminho está em aporia. Nada poderia demonstrar de maneira mais evidente as diferenças essenciais entre os dois caminhos teóricos do que essas duas constatações.

Por sua vez, o que pode elucidar essa variação já não é tão evidente. 0 próprio fato de que as duas obras foram escritas em línguas diferentes, para públicos diferentes, pode ter sido um elemento bem mais importante do que se pode crer à primeira vista. Sem dúvida, escrito para o público americano e publicado por uma editora prestigiosa como a de Oxford, Eclipse da razão "foi um livro que queria ser outra coisa que uma 'mensagem na garrafa'”, como James Schmidt sustenta, referindo-se uma conhecida caracterização da Dialética do esclarecimento (Schmidt, 2007, p.49). Schmidt insiste na reação de Horkheimer às questões levantadas pelo público das conferências, a qual deixou vestígio na elaboração do livro. 
Por outro lado, talvez a mão de Adorno no livro escrito em conjunto tenha pesado mais para uma via "nietzschiana". ${ }^{8} \mathrm{Em}$ todo caso, cabe lembrar que a figura de Nietzsche é presente desde cedo no pensamento de Horkheimer, como um pensador que, a cada vez, ele vai concedendo um pouco mais. ${ }^{9}$

A meu ver, as expectativas diferentes que as duas obras envolvem só podem ser explicadas de maneira convincente a partir do diagnóstico que Horkheimer faz das tendências emancipatórias. A crítica da esquerda foi o limiar da crítica da razão, uma vez que ela conduziu à suspeita sistemática de todo o processo de racionalização, sem, contudo, abandonar o campo da esquerda em que se situa a Teoria Crítica. As duas vias diferentes correspondem ao campo de tensão que é criado pelo diagnóstico político de Horkheimer, realizado dentro das coordenadas da Teoria Crítica.

De um lado, a via nietzschiana faz da aporia, paradoxalmente, um princípio de utopia. É porque Nietzsche identifica razão e dominação que algo de utópico do conceito de razão ainda pode emergir. Como Horkheimer afirma no final do ensaio sobre Juliette, a insistência nietzschiana sobre a razão tem o "sentido secreto de libertar de seu invólucro a utopia contida, como no conceito kantiano de razão, em toda grande filosofia: a utopia de uma humanidade que, não sendo mais desfigurada, não precisa mais desfigurar o quer que seja" (Horkheimer, Adorno, 1947, p.112).

De outro lado, a via kantiana parece mais adequada, mas em um sentido político e metodológico ainda muito impreciso, para a perspectiva emancipatória contida no conceito de razão. Ela ainda está ligada aos motivos que lhe deram origem: a configuração racional do mundo não precisa ter a forma do pior dos mundos, é possível, no nível intelectual, romper as injunções que separam a razão subjetiva e a objetiva.

\section{Referências}

Abromeit, J. (2011). Max Horkheimer and the Foundations of the Frankfurt School. Cambridge: Cambridge University Press.

Dubiel, H. (1978). Wissenschaftsorganisation und politische Erfahrung. Studien zur frühen Kritischen Theorie. Frankfurt am Main: Suhrkamp.

Genel, K. (2013). Autorité et emancipation - Horkheimer et la Théorie Critique. Paris: Payot.

Habermas, J. (1987). Theorie des kommunikativen Handelns. Band I. Handlungsrationalität unde gesellschaftliche Rationalisierung. Frankfurt am

\footnotetext{
8 Abromeit defende a tese de que é a influência de Adorno que será decisiva para a compreensão da produção teórica de Horkheimer nesse período. Cf. Abromeit, 2011, pp.349 ss. Sobre as diferenças entre Horkheimer e Adorno que ainda repercutem na Dialética do esclarecimento, cf. Habermas, 2015, pp.143ss, apesar da tese interpretativa que o autor defende, mencionada acima.

9 A dívida do Horkheimer de "Egoísmo e movimento de libertação" para com Nietzsche é sublinhado por ele mesmo em uma carta a Katharina von Hirsch, de fevereiro de 1936. Cf. Horkheimer, 2008, pp.60ss.
} 
Main: Suhrkamp.

. (2000). O discurso filosófico da modernidade. Tradução de Luiz Repa e Rodnei do Nascimento. São Paulo: Martins Fontes.

(2015). "Max Horkheimer: sobre a história do desenvolvimento de sua obra”. In: Textos e contextos. Tradução de Antonio lanni Segatto. São Paulo: Unesp.

Horkheimer, M., Adorno, T. (1947). Dialektik der Aufklärung. Philosophische Fragmente. In: Gesammelte Schriften. Vol. 5. Frankfurt am Main: Fischer, 1987.

Horkheimer, M. (1931). "Die gegenwärtige Lage der Sozialphilosophie und die Aufgaben eines Instituts für Sozialforschung”. In: Gesammelte Schriften. Vol. III. Frankfurt am Main: Fischer, 1988.

. (1936a). “Autorität und Familie”. In: Gesammelte Schriften. Vol. III. Frankfurt am Main: Fischer, 1988.

(1936b). Egoismus und Freiheitsbewegung. Zur Anthropologie des bürgerlichen Zeitalters. Zeitschrift für Sozialforschung, 5, caderno 2. Reimpressão pela Deutscher Taschenbuch Verlag, 1980.

(1937). Traditionelle und kritische Theorie. Zeitschrift für Sozialforschung. 6, caderno 2. Reimpressão pela Deutscher Taschenbuch Verlag, 1980.

. (1938). Montaigne und die Funktion der Skepsis. Zeitschrift für Sozialforschung. VII, caderno $1 / 2$.

- (1939). Die Juden und Europa. Studies in Philosophy and Social Science, 8, caderno 1. Reimpressão pela Deutscher Taschenbuch Verlag, 1980.

. (1940). “Autoritärer Staat”. In: Gesammelte Schriften. Vol. V. Frankfurt am Main: Fischer, 1987.

. (1941a). The End of Reason. Studies in Philosophy and Social Sciences.

9(3). Versão alemã (1942): “Vernunft und Selbserhaltung”. In: Gesammelte Schriften. Vol 5. Frankfurt am Main: Fischer, 1987.

(1941b). Preface. Studies in Philosophy and Social Sciences, 9, (2). Reimpressão pela Deutscher Taschenbuch Verlag, 1980.

janeiro de 2016.

. (1943). “On the Sociology of Class Relations". In: nonsite.org, 18, . (1947). Eclipse of Reason. London: The Continuum, 2004.

(2008). A life in letters. Selected Correspondence. Lincoln/Londres:

University of Nebraska Press.

Jay, M. (2008). A imaginação dialética. História da Escola de Frankfurt e do Instituto de Pesquisas Sociais - 1923-1950. Rio de Janeiro: Contraponto.

Marramao, G. (1975). Political Economy and Critical Theory. Telos, 24, pp.56-80.

Marin, I., Nobre, M. (2012). Uma nova antropologia. Unidade crítica e arranjo interdisciplinar na Dialética do Esclarecimento. Cadernos de filosofia alemã, 20, pp.101-122. 
Nobre, M. (1996). "Lukács e o materialismo interdisciplinar". In: Antunes, R., Rego, W. L. (orgs.). Lukács - um Galileu no século XX. São Paulo: Boitempo. . (1998). A dialética negativa de Theodor W. Adorno. A ontologia do estado falso. São Paulo: Iluminuras. . (2008). "Max Horkheimer: A Teoria Crítica entre o nazismo e o capitalismo tardio". In: Nobre, M. (org.). Curso livre de Teoria Crítica. Campinas: Papirus.

Petry, F. B. (2013). O conceito de razão nos escritos de Max Horkheimer. Cadernos de filosofia alemã, 22, pp.31-48.

Pollock, F. (1941). State Capitalism: its Possibilities and Limitations. Studies in Philosophy and Social Sciences, IX (2).

Postone, M., Brick, B. (1993). "Critical Theory and Political Economy". In: Benhabib, S., Bonss, W., McCole, J. (orgs.) On Max Horkheimer. New Perspectives. Cambridge, Londres: The MIT Press.

Rosa, L. (2011). "Questões de organização da social-democracia russa”. In: Loureiro, I. (org.). Rosa Luxemburgo - textos escolhidos. Vol. I. São Paulo: Unesp.

Rugitsky, F. (2008). "Friedrich Pollock: limites e possibilidades". In: Nobre, M. (org.). Curso livre de Teoria Crítica. Campinas: Papirus.

Stirk, P. (1992). Max Horkheimer: a new Interpretation. Hemel Hempstead/Lanham: Harvester Wheatsheaf/Barnes \& Noble Books.

Schmidt, J. (2007). The Eclipse of Reason and the End of the Frankfurt School in America. New German Critique, 100, pp.47-76.

Wiggershaus, R. (1994). The Frankfurt School: Its History, Theories, and Political Significance Studies in Contemporary German Social Thought. Cambridge: The MIT Press. 